\title{
Assessing the Impacts of Climate Change on Future Precipitation Trends Based on Downscaled CMIP5 Simulations Data
}

\author{
GHULAM HUSSAIN DARS*, MOHAMMAD REZA NAJAFI**, AND ABDUL LATIF QURESHI* \\ RECEIVED ON 07.09.2016 ACCEPTED ON 22.11.2016 \\ ABSTRACT
}

\begin{abstract}
This study investigates future changes in precipitation over the CRB (Columbia River Basin) in both wet (DJF) and dry (JJA) seasons under RCP85 GHG emission scenario. The simulations from four climate models which participated in CMIP5 (Coupled Model Intercomparison Project Phase-5) were downscaled using the BCSD (Bias Correction and Spatial Disaggregation) method. After downscaling, extreme value analysis and MME (Multi Model Ensemble) averaging is performed. This study focuses on computing 2, 5, 10 and 25 years return levels for both winter (DJF) and summer (JJA) seasons. The maximum winter precipitation values for $2,5,10$ and 25 years return periods have been estimated to be about 112 , 127,148 and $171 \mathrm{~mm} /$ day respectively whereas the maximum summer precipitation values for $2,5,10$ and 25 years return periods are observed to be about 56, 81,96 and $126 \mathrm{~mm} / \mathrm{day}$ respectively. The MME average outperformed the individual models in simulating the historical precipitation in both seasons. The MME results showed a consistent and significant increase in the extreme precipitation and decrease in mean precipitation in both future wet and dry seasons. Largest increase in precipitation occurs over the higher elevations of the Cascades Range, Coast Range and the Mountainous Range.
\end{abstract}

Key Words: Climate Change Impact, Coupled Model Inter Comparison Project Phase-5, Precipitation, Columbia River Basin, Bayesian Model Averaging

\section{INTRODUCTION}

I

is widely accepted that the warming due to climate change intensifies the water cycle and increases the frequency of extreme wet and dry events [1]. Extreme precipitation changes are one of the major climate change concerns as they can seriously affect the human lives, agriculture, livestock and socio-economics. In the United States, historical records demonstrate that the intensity and frequency of extreme precipitation events have increased in the second half of the twentieth century [2]. The studies project possible declines in the mean precipitation and increase in the extreme precipitation in this region in the future [2-4].

Despite the high level of development and management, the Columbia River is vulnerable to climate change [5]. Climate change and variability affects the total runoff due to changes in the spatial and temporal patterns of precipitation which may eventually increase water

\footnotetext{
* $\quad$ US-Pakistan Centers for Advanced Studies in Water, Mehran University of Engineering \& Technology, Jamshoro.

** Pacific Climate Impacts Consortium, University of Victoria, Canada.
}

Mehran University Research Journal of Engineering \& Technology, Volume 36, No. 2, April, 2017 [p-ISSN: 0254-7821, e-ISSN: 2413-7219] 
demands between various competing water sectors. Dominguez et. al. [2] examined the impact of climate change on winter precipitation extremes in the western United States using RCM (Regional Climate Models) wherein they found a consistent and significant increase in the intensity of future extreme winter precipitation and heterogeneous patterns in mean winter precipitation.

GCMs (General Circulation Models) are the primary tools to analyze possible future impacts of climate change. However, because of having the coarse resolution, GCMs can't represent climate variables at local or regional scales and therefore, downscaling is needed. For this research, GCM simulations data were obtained from the CMIP5 archive. CMIP5 is the most updated climate data archive and contains huge data to conduct research on climate change impact [6] and is issued in the IPCC (Intergovernmental Panel on Climate Change) AR5 (Fifth Assessment Report). In CMIP5 data archive, new type of greenhouse gas emission scenarios have been introduced i.e. RCPs (Representative Concentration Pathways). Although being updated and improved in spatial resolution, CMIP5 simulations contain considerable biases and uncertainties which are mainly due the model initialization, observation errors, and inappropriate data assimilation procedures techniques [7].This study evaluates precipitation changes over the CRB for both wet (DJF) and dry (JJA) seasons by using the MME average for the future period of 2041-2070 under RCP85 GHG (Greenhouse Gases) scenario. Relying on one model may lead to several uncertainties. Therefore, a MME averages are getting more popular in climate modeling community because MME reduces the uncertainty to a larger degree.

MME methods are widely used in many fields of economics, meteorology and hydrology [8-10]. The performance of the earlier MME techniques is not satisfactory because the weights obtained by these methods were not based on performance of the model [10]. Hoeting et. al. [11] have developed an MME approach called as BMA (Bayesian Model Averaging) which computes weights based on the performances of model. The BMA is an efficient method which determines both the within-model variance and between-model variance. This method has been applied in various fields including statistics, hydrology, groundwater modeling, meteorology, medicine and management science [10,12-14]. This research could be helpful for planning and sustainable water resources management under the likely impact of climate change in this basin.

Relating to the above discussion, the current paper will explore following research questions:

(i) What are the climate change impacts on future precipitation trends in CRB using updated climate models data?

(ii) Does MME averages (BMA) perform better than individual models in assessing climate change impacts?

\section{MATERIALS AND METHOD}

\subsection{Study Area}

The Columbia River, having a length of 1243 miles, originates from the Columbia Lake in the Canada and finally drains into Pacific Ocean. It has a length of 1243 miles and is spread into British Columbia, a Province of Canada and seven states of the US [15]. Because of favorable location, the $\mathrm{CRB}$ receives a large amount of precipitation and carries an average annual water of 200 million acre-feet [17]. The CRB receives major part of the precipitation in the winter season which contributes to the peak runoff in the late spring and early summer. It irrigates about 1.4 million hectares [18] (Fig. 1). 


\subsection{Methodology}

The study analyzes change in precipitation patterns for the CRB for the future period of 30 years (2041-2070) based on the historical data for the period 30 years (1970-1999) using BMA MME. MME of four models means combination of four models with one member of each model. The methodology includes data collection, bias correction and downscaling, extreme value analysis and MME.

\subsubsection{Datasets}

GCM simulations data of four models has been collected from the CMIP5 archive. The CMIP5 is the most updated climate data archive and contains a huge number of data to conduct the research on climate change impact analysis. In CMIP5 data archive, new types of GHG emission scenarios have been introduced named as RCPs which

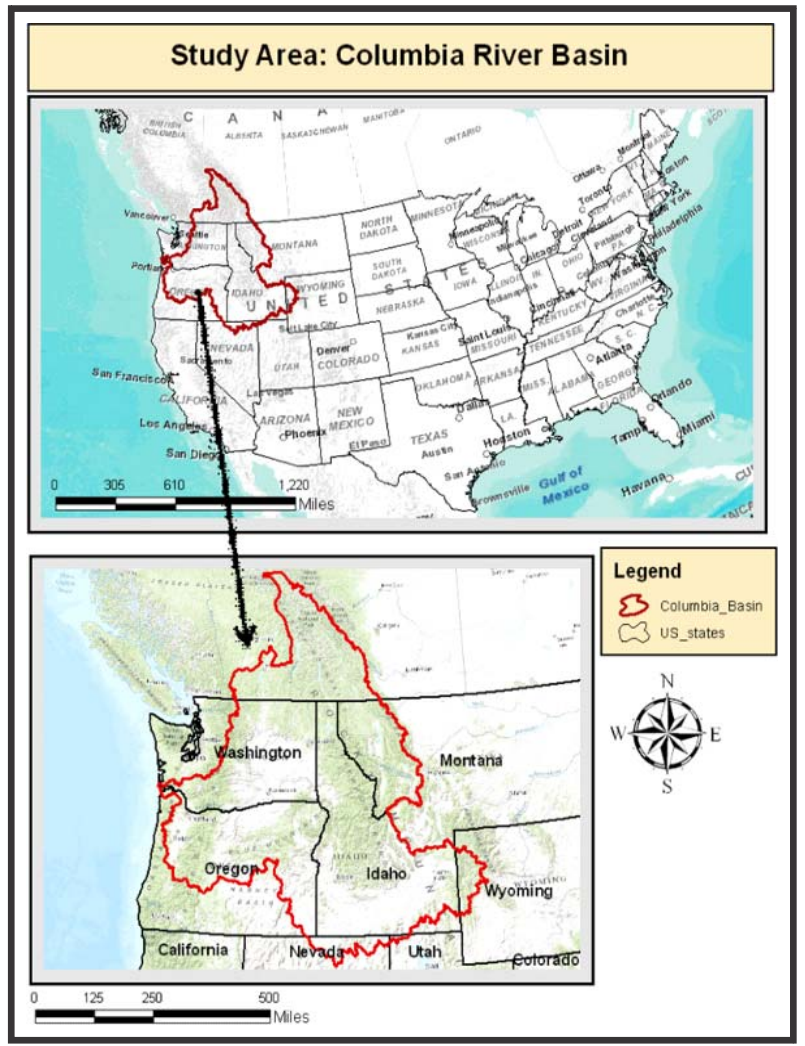

are more comprehensive compared to previous GHG scenarios known as SRES (Special Report on Emission Scenarios). According to Taylor et. al. [6], the main objective behind the selection of this name is to provide time-dependent projections of GHG concentrations at the end of the 21 st century. In this study, four GCM simulations have been used to predict precipitation patterns for the future period of 30 years i.e. 2041-2070 under the GHG scenario of RCP 85. The observed gridded precipitation data for this study has been taken from University of Washington's website which has resolution of $1 / 16^{\circ}[19]$ (Table 1 ).

\subsubsection{Downscaling}

GCMs (Global Climate Models) are the primary tools to assess the likely impacts of climate Change. Predicting or forecasting the likely impact of climate change on

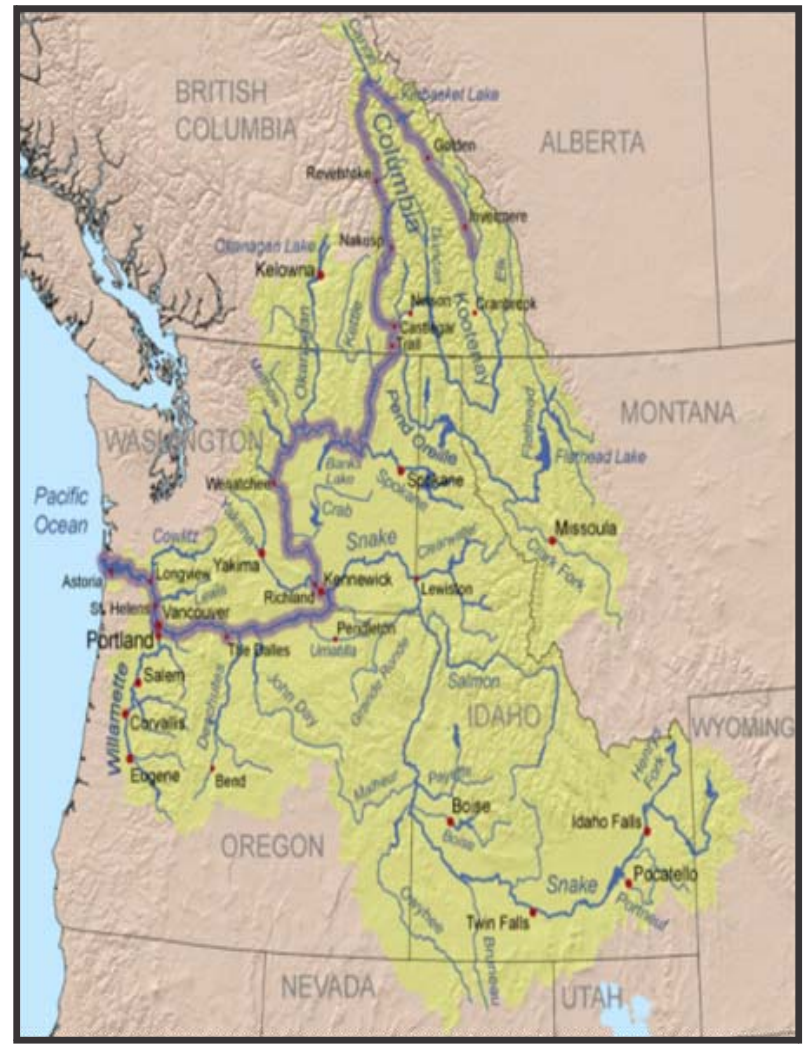

FIG. 1. STUDY REA: COLUMBIA RIVER BASIN [16]

Mehran University Research Journal of Engineering \& Technology, Volume 36, No. 2, April, 2017 [p-ISSN: 0254-7821, e-ISSN: 2413-7219] 
precipitation patterns is quite a challenging job because they have very coarse resolution ranging from 125-300 $\mathrm{km}$ which makes them unable to predict the likely impact of climate change effects on regional or local scales accurately. Despite some improvements in spatial resolution and other advances in climate models, CMIP5 models contain considerable bias. Therefore, downscaling is required to bias correct and downscale the models. Downscaling can be defined as the process of relocating the coarse resolution climate model data to the fine spatial scale data to do local analyses of climate effects [20]. There are two approaches for downscaling climate models known as dynamical and statistical downscaling. The dynamical downscaling methods involve nesting of RCMs with GCMs to produce downscaled high resolution outputs and statistical downscaling methods requires developing robust statistical relationships between the coarse-resolution climate model and fine-resolution local climate variables. Statistical downscaling methods are widely used because of being computationally efficient, cheaper, and applicable for multiple GCMs [20-21]. The statistical downscaling methods are classified as regression models, weather typing schemes and weather generators. The regression models involve development of the transfer functions between GCM simulated and observed data. This study implemented BCSD (Bias Correction and Spatial Disaggregation) method to downscale the climate models which is described below:

BCSD Downscaling: This study adopts the BCSD method [22-23] to downscale the climate simulation. The future time period of 30 years i.e. 2041-2070 has been selected because it is close enough to be of interest to stakeholders and far enough to extend beyond decades where natural variability likely dominates over climate change. The RCP 8.5 scenario has been adopted in this study which is projected to be stabilized at $8.5 \mathrm{~W} / \mathrm{m}^{2}$ at the end of $21 \mathrm{st}$ century. The quantile mapping in BCSD method involves categorizing of the GCM simulated data and observed data in CDFs (Cumulative Distribution Functions). Then, the transfer factors are developed between simulated and observed data at each grid. This serves as mapping of the GCM simulations data over the observed data at each grid. These transfer factors are then applied to the future simulated data to bias correct and downscale the data at each grid. In this downscaling method, multiplicative perturbations are adopted for precipitation. At the end, the resolution of the downscaled data will be similar to that of observed data i.e. $1 / 16^{\circ}$.

\subsubsection{Extreme Value Analysis}

The detection of possible future changes in extreme events due to climate change has now become essential part of water resources planning and management. It helps evaluate the historical data and predict the future probabilities of extreme events. The GEV (Generalized Extreme Value) distribution [24] is one of the most widely used distributions in extreme value analysis. Many studies show that the GEV distribution is capable of simulating historical extreme events and predicting future extreme events [25-27]. Many renowned researchers have used GEV distribution to analyze extreme precipitation and temperature [4,28-31].

TABLE 1. CMIP5 MODELS AND THEIR RESOLUTIONS

\begin{tabular}{|c|c|c|}
\hline No. & Model/GCM Name & Resolution (Long x Lat) in Degrees \\
\hline 1. & ACCESS 1.0 (Australian Community Climate and Earth-System Simulator) & $1.875 \times 1.25$ \\
\hline 2. & BCC-CSM 1.1 (Beijing Climate Center - Climate System Model) & $2.8 \times 2.8$ \\
\hline 3. & CCSM4 (Community Climate System Model) & $0.94 \times 1.25$ \\
\hline 4. & CanESM2 (Canadian 2nd generation Earth System Model) & $2.8 \times 2.8$ \\
\hline
\end{tabular}

Mehran University Research Journal of Engineering \& Technology, Volume 36, No. 2, April, 2017 [p-ISSN: 0254-7821, e-ISSN: 2413-7219] 
In this research, GEV distribution comprised of three extreme value distributions named Gumbel, Frechet, Weibull distributions has been used to evaluate extreme precipitation. The GEV distribution has been fitted for each season separately, and then return period of extreme events have been estimated.

The CDF of the GEV distribution is as follows:

$$
\begin{aligned}
& \left.\mathrm{F}(\mathrm{x}, \mu, \delta, \xi)=\exp \left(-\frac{\mathrm{x}-\mu}{\delta}\right)\right] \text { when } \xi \equiv 0 \\
& \mathrm{~F}(\mathrm{x}, \mu, \delta, \xi)=\exp \left[-\left(1+\xi-\frac{\mathrm{x}-\mu}{\delta}\right)^{-\frac{1}{\xi}}\right] \text { when } \xi \neq 0
\end{aligned}
$$

Where $\mu$ is the location parameter, $\xi$ is the shape parameter and $\delta$ is the scale parameter. According to Katz et. al. [27], shape parameter can be used to describe the tail behavior of the distribution. If $\xi=0, \mathrm{GEV}$ is called Type-I or Gumbel distribution. If $\xi>0$, GEV distribution is called Type-II or Frechet distribution. If $\xi<0$, GEV distribution is termed Type-III or Weibull distribution. Some studies have proved that at least 25 annual maximum values are required for the GEV distribution for best performance [25-26].

\subsubsection{Multi-Modeling Ensemble}

Usually, hydrologists rely on single model whereas it may lead to unreliable and uncertain hydrologic forecasts because models may contain bias and structural errors [32-34]. In this research, BMA technique is used for MME technique. The research has shown that the BMA technique produces more reliable and realistic predictions because it involves both betweenmodel variance and in-model variance [10,34]. The obtained weights are weighted averages of the individual models, and its sum is equal to 1 because they are probabilistic likelihoods of a model.
If a variable $y$ is to be forecasted, then according to the law of total probability the PDF (Probability Distribution Function) of the variable y can be expressed as:

$\mathrm{P}\left(\frac{\mathrm{y}}{\mathrm{O}}\right)=\sum_{i=1}^{I} \mathrm{p}\left(\frac{\mathrm{y}}{\mathrm{mi} . \mathrm{O}}\right) \cdot \mathrm{p}\left(\frac{\mathrm{mi}}{\mathrm{O}}\right)$

Where $\mathrm{p}\left(\mathrm{y} / \mathrm{m}_{\mathrm{i}} \mathrm{O}\right)$ is the posterior distribution of $\mathrm{y}$ based on model prediction $\left(\mathrm{m}_{\mathrm{i}}\right)$ at each grid (i) and the observation data $(\mathrm{O}) \cdot \mathrm{p}\left(\mathrm{m}_{\mathrm{i}} \mathrm{O}\right)$ is the posterior probability of model prediction $\left(\mathrm{m}_{\mathrm{i}}\right)$.

In this procedure, the conditional probability distribution $\mathrm{p}\left(\mathrm{y} / \mathrm{m}_{\mathrm{i}} \mathrm{O}\right)$ should be considered to be Gaussian, and if it is not Gaussian distribution, Box-Cox transformation should be used to transform both modeled and observed data close to the Gaussian distribution before implementing the BMA technique. The obtained weights show the performance of each model; the higher weights show the better performance of the model. More detail about BMA is given in [10].

\section{RESULTS}

This study focuses on computing 2, 5, 10 and 25 years return levels for both winter (DJF) and summer (JJA) seasons. The maximum values for 2, 5, 10 and 25 years return periods among all four models are found to be about 84, 108, 123 and $156 \mathrm{~mm} /$ day, respectively. The models consistently show increase in winter extreme precipitation over the higher elevations of the Cascade Range, Coast Range and Mountainous Range. On the other hand, the four models showed heterogeneous spatial pattern of the future changes in the extreme precipitation for the summer season. The CCSM4 model showed an increase only over the Rocky Mountains in the Idaho State and decline in the extreme precipitation over the other domain of CRB for the summer season. 
The ACCESS1.0 model showed an increase over the Canadian portion of the basin and Rocky Mountains Ranges and decline in the extreme precipitation over the other domain of CRB. The CanESM2 and BCC-CSM1.1 models showed an increase in the extreme precipitation in the summer season over the whole basin. Figs. 2-3 shows winter and summer return levels for 2 and 25 year return periods respectively.

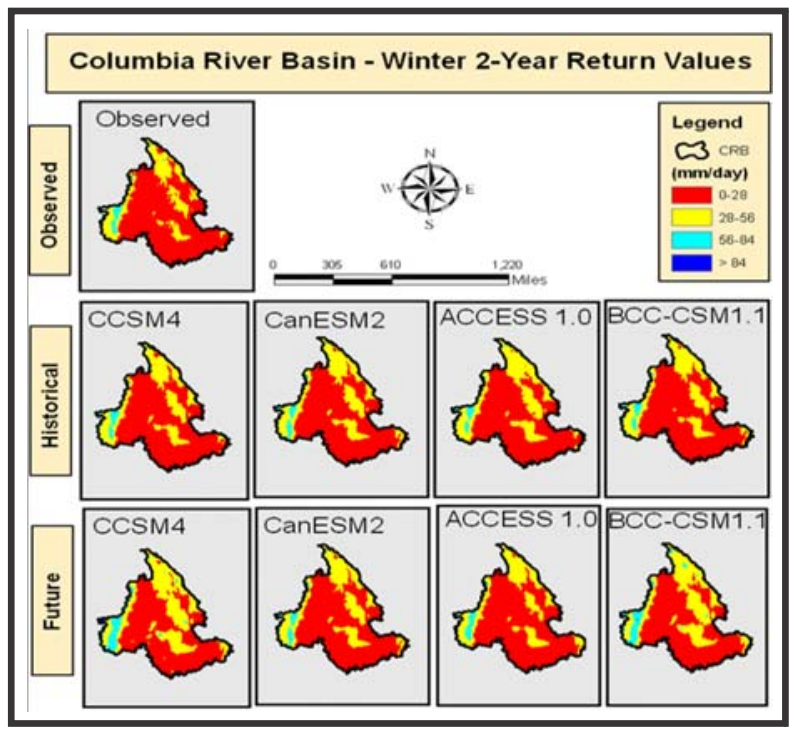

\section{MULTI-MODELING ENSEMBLE RESULTS}

The main focus of this study was to estimate the changes in precipitation patterns for both winter and summer season for the future period of 30 years i.e. 2041-2070 by using the BMA MME technique over the domain of the Columbia River Basin. BMA estimates weights of individual models based on their probabilistic likelihood measures so sum of

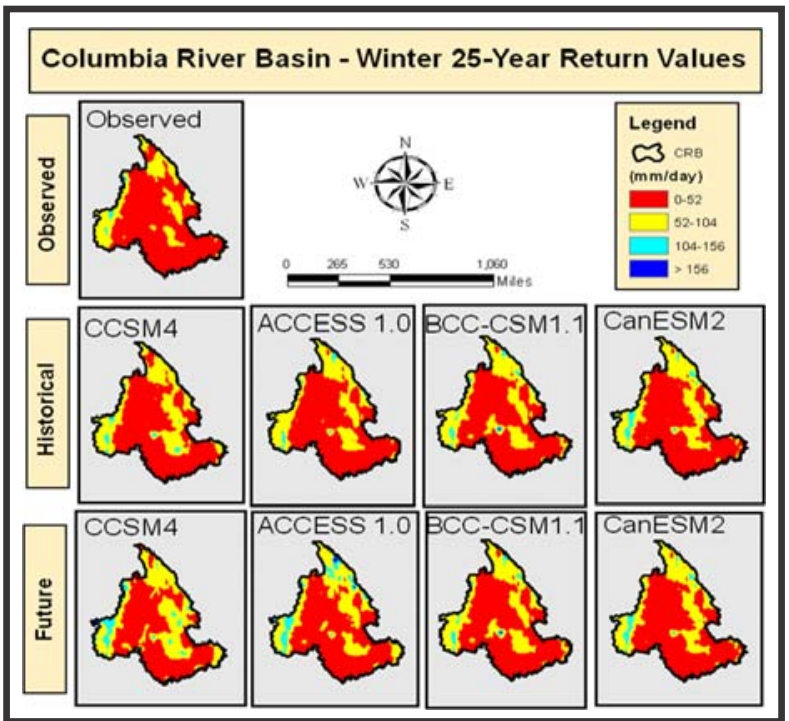

FIG. 2. 2-YEAR AND 25-YEAR RETURN LEVELS FOR WINTER SEASON
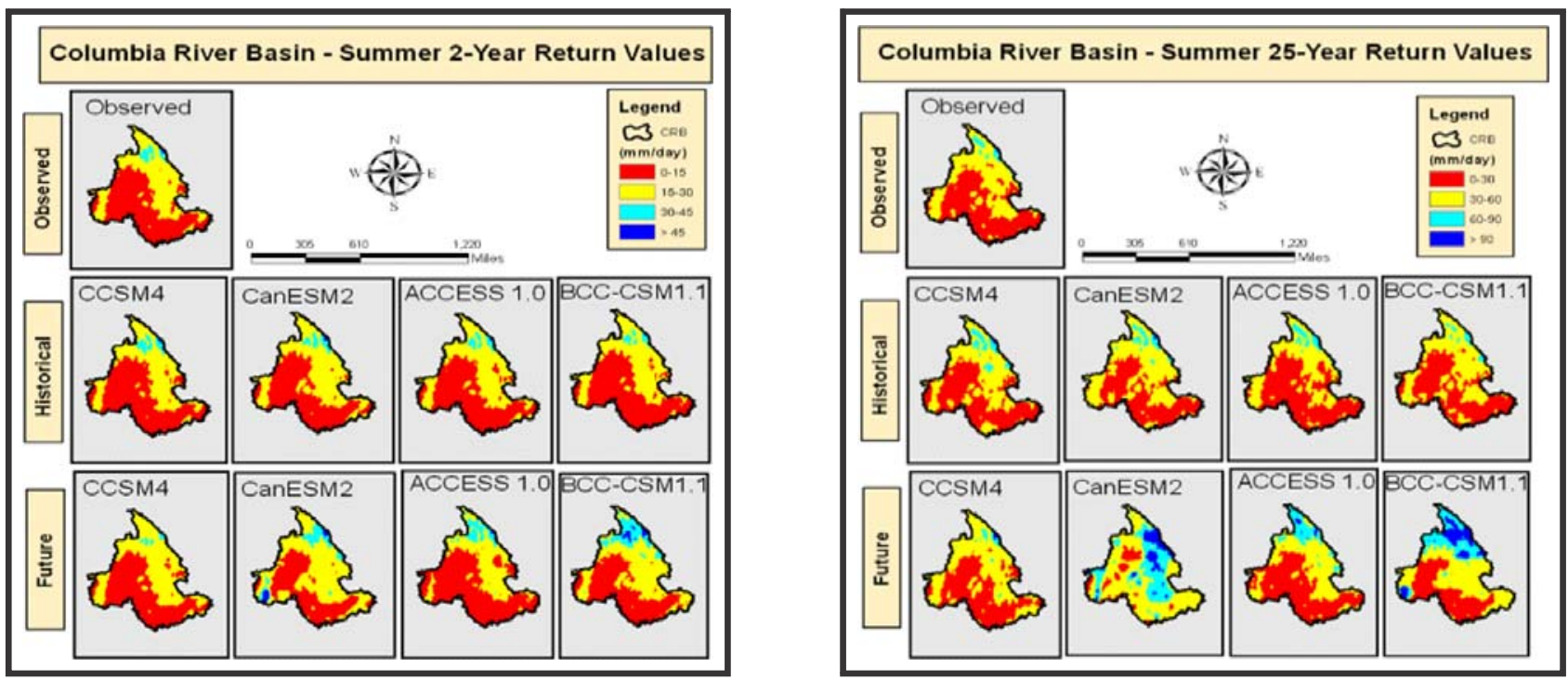

FIG. 3. 2-YEAR AND 25-YEAR RETURN LEVELS FOR SUMMER SEASON

Mehran University Research Journal of Engineering \& Technology, Volume 36, No. 2, April, 2017 [p-ISSN: 0254-7821, e-ISSN: 2413-7219] 
all weights will be equal to 1 . The models which perform better will get higher weights than the models performing worse. Fig. 4 indicates the weights of four models which shows that the CCSM4 model performed better than all other three models. It can be observed from Fig. 5 that MME historical values are nearly similar to the observed values which shows that the MME averages outperformed compared to the individual performance of climate models for historical period. Moreover, The maximum winter precipitation values for 2, 5, 10 and 25 years return periods are found to be about $112,127,148$ and $171 \mathrm{~mm} /$ day, respectively whereas the maximum summer precipitation values for 2, 5, 10 and 25 years return periods are observed to be about 56, 81, 96 and $126 \mathrm{~mm} /$ day, respectively which can be seen in Fig. 6. Moreover, from Fig. 4, it can be observed that the increasing trend was observed in extreme precipitation for the both winter and summer seasons in whole basin with maximum increase over the higher elevations of the Cascades Range, Coast Range and the Mountainous Range. Whereas, the MME average results showed decrease in mean precipitation for both seasons. The mean precipitation was projected to be decreased by $2.47 \%$ decrease in the winter season and $8.7 \%$ decrease in summer season for future period. It showed that the mean precipitation was projected to decrease more in summer season.

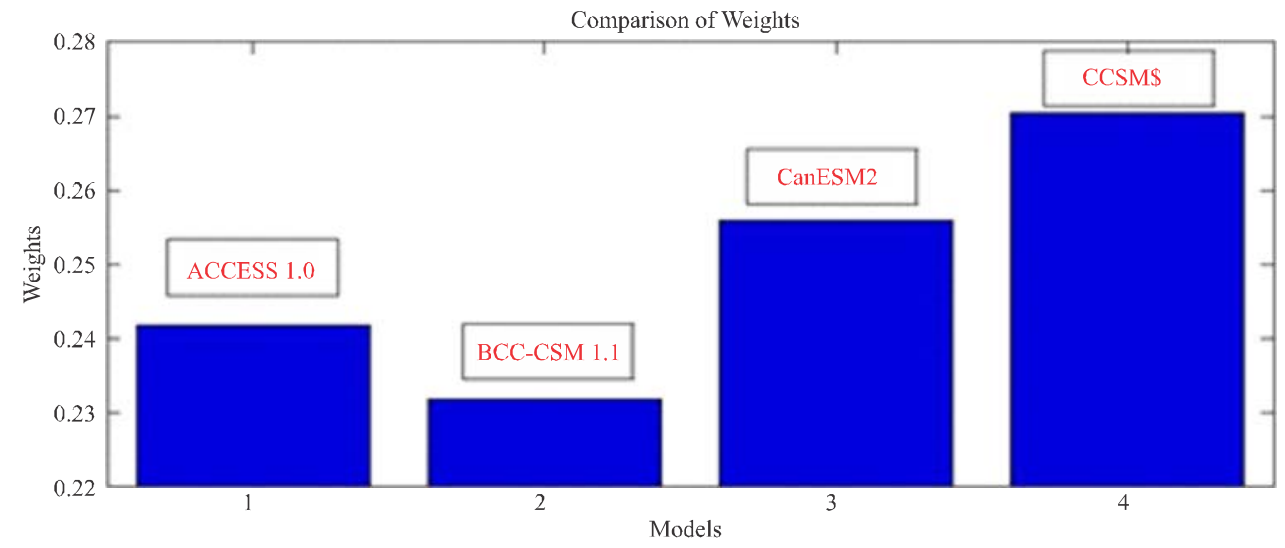

FIG. 4. WEIGHTS OF FOUR MODELS OBTAINED FROM BMA TECHNIQUE
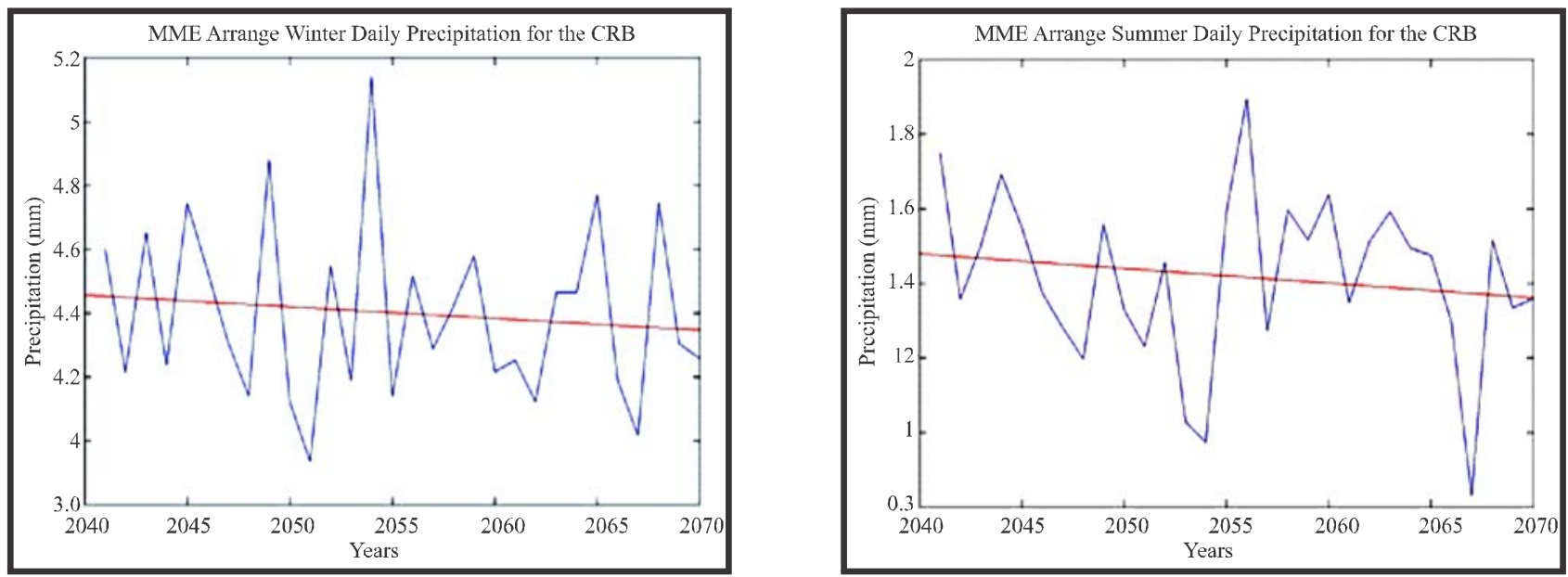

FIG. 5. MME MEAN PRECIPITATION FOR WINTER (LEFT) AND SUMMER SEASON (RIGHT) FOR CRB 

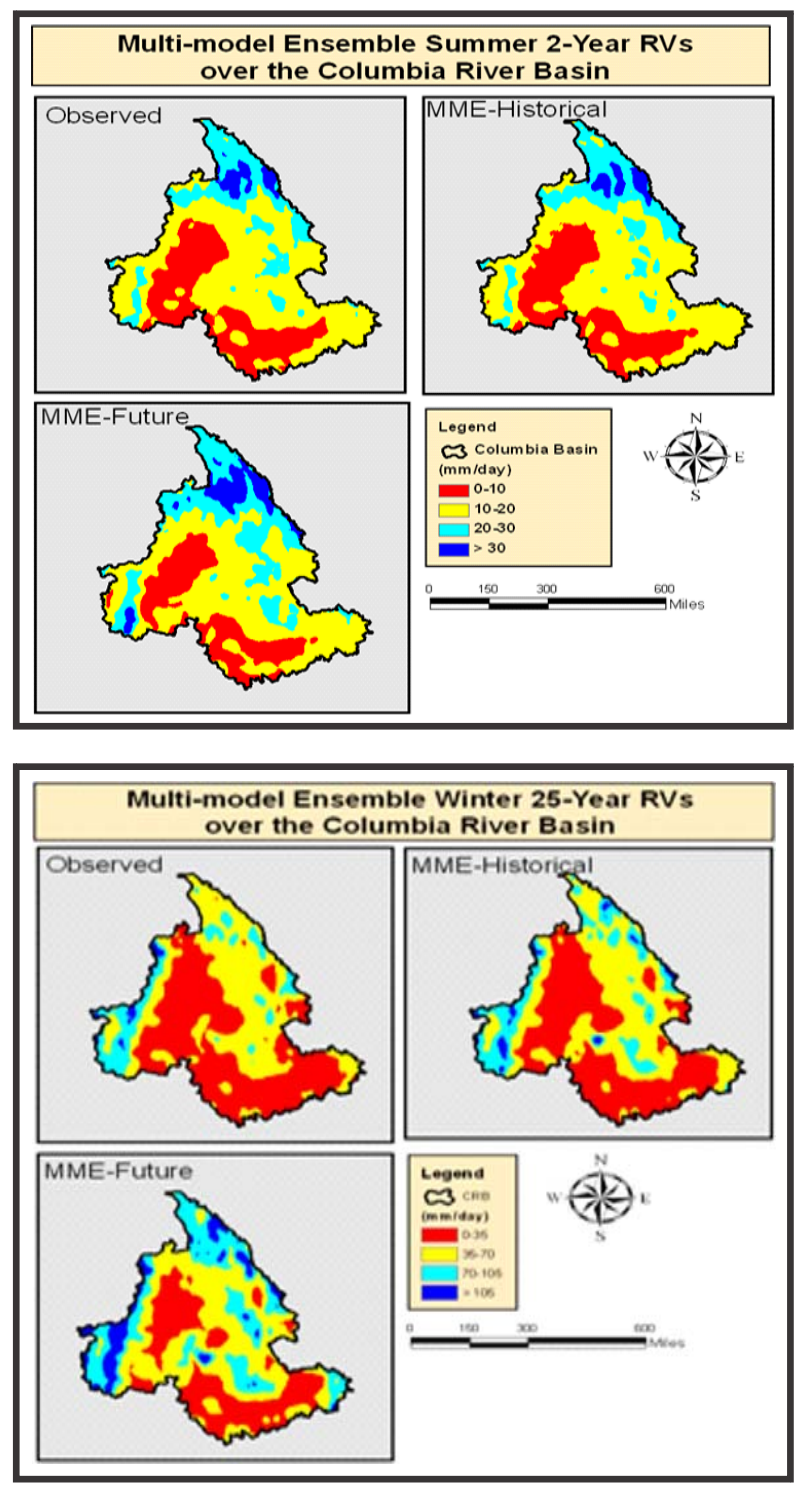
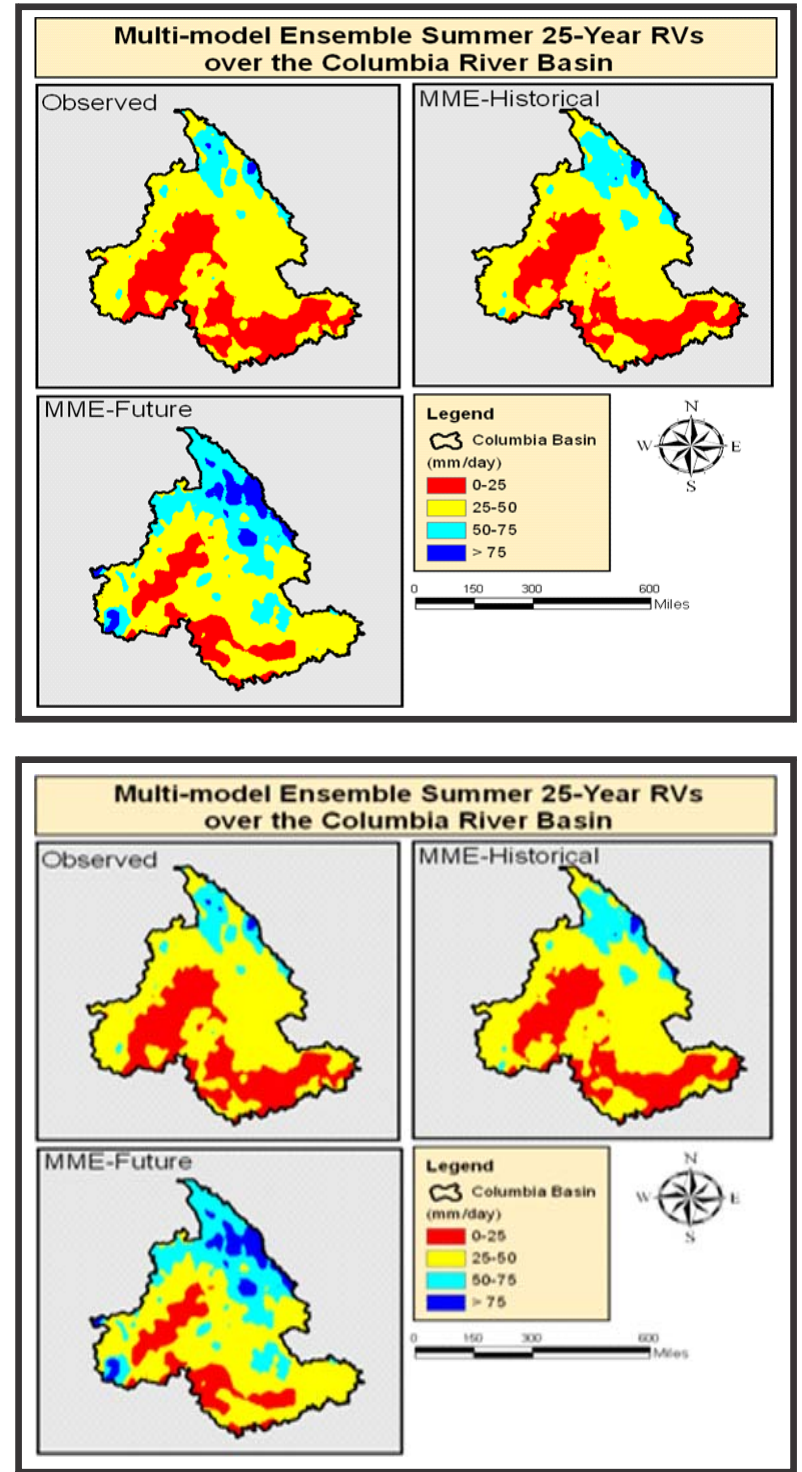

FIG. 6. MME RESULTS FOR 2 AND 25 YEARS RETURN PERIODS FOR WINTER AND SUMMER SEASONS

\section{CONCLUSION}

The results showed a consistent and significant increase in the extreme precipitation and decrease in mean precipitation in both future wet and dry seasons which supports the previous research discussed in the introduction part of this article. Largest increase in precipitation occurs over the higher elevations of the Cascades Range, Coast Range and the Mountainous Range. The results also indicate that we cannot rely on one model because each model produces different results. BMA method is proved to be an efficient method to quantify the model structure uncertainties and perform MME. This method is successfully applied in present study to quantify models' uncertainty in terms of weights. Water managers, experts and policy makers are interested to quantify models' behavior and uncertainty in climate change impact analysis and this study will help them achieve this goal. In this study, only four models were studied due to having limited computational resources 
because BMA model simulations on four models take 2-3 days to run so it will take more time to produce results when more GCMs are added. However, to get more precise and accurate results, it is suggested to add more GCM models in future studies. In addition, calibration and validation of historical data is very critical in any model application. In this study, calibration has been performed by using entire historical data of 30 years but validation has not performed. Therefore, it is also suggested that in future studies, calibration and validation may be performed to get better results. For example, taking the 30 year data set $60-70 \%$ of the data could be chosen for calibration and fit the BMA and find the weights corresponding to each model then apply those weights to the model in the validation period and compare the results with the observations.

\section{ACKNOWLEDGEMENT}

Authors acknowledge the World Climate Research Program's Working Group on Coupled Modeling, which is responsible for CMIP, and we thank the climate modeling groups for producing and making available their model output. For CMIP the US Department of Energy's Program for Climate Model Diagnosis and Intercomparison provides coordinating support and led development of software infrastructure in partnership with the Global Organization for Earth System Science Portals.

\section{REFERENCES}

[1] Huntington, T.G., "Evidence for Intensification of the Global Water Cycle: Review and Synthesis", Journal of Hydrology, Volume 319, No. 1, pp. 83-95, 2006.

[2] Dominguez, F., Rivera, E., Lettenmaier, D.P., and Castro, C.L., "Changes in Winter Precipitation Extremes for the Western United States under a Warmer Climate as Simulated by Regional Climate Models", Geophysical Research Letters, Volume 39, No. 5, 2012

[3] Emori, S., and Brown, S.J., "Dynamic and Thermodynamic Changes in Mean and Extreme Precipitation under Changed Climate", Geophysical Research Letters, Volume 32, No. 17, 2005.
[4] Najafi, M.R., and Moradkhani, H., "Analysis of Runoff Extremes using Spatial Hierarchical Bayesian Modeling", Water Resources Research, Volume 49, No. 10, pp. 6656-6670, 2013.

[5] Cohen, S.J., Miller, K.A., Hamlet, A.F., and Avis, W., "Climate Change and Resource Management in the Columbia River Basin", Water International, Volume 25, No. 2, pp. 253-272, 2000.

[6] Taylor, K.E., Stouffer, R.J., and Meehl, G.A., "An Overview of CMIP5 and the Experiment Design", American Meteorological Society, Volume 93, No. 4, pp. 485-498, 2012.

[7] Rana, A., and Moradkhani, H., "Spatial, Temporal and Frequency Based Climate Change Assessment in Columbia River Basin Using Multi Downscaled-Scenarios”, Climate Dynamics, pp. 1-22, 2015.

[8] Bates, J.M., and Granger, C., "The Combination of Forecasts", Operational Research Society, Volume 20, No. 4, pp. 451-468, 1969.

[9] Dickinson, J.P., "Some Statistical Results in the Combination of Forecasts", Journal of the Operational Research Society, Volume 24, No. 2, pp. 253-260, 1973.

[10] Duan, Q., Ajami, N.K., Gao, X., and Sorooshian, S., "Multi-Model Ensemble Hydrologic Prediction Using Bayesian Model Averaging", Advances in Water Resources, Volume 30, No. 5, pp. 1371-1386, 2007.

[11] Hoeting, J.A., Madigan, D., Raftery, A.E., and Volinsky, C.T., "Bayesian Model Averaging: A Tutorial", Statistical Science, pp. 382-401, 1999.

[12] Fernandez, C., Ley, E., and Steel, M., "Benchmark Priors for Bayesian Model Averaging", Journal of Econometrics, Volume 100, No. 2, pp. 381-427, 2001.

[13] Viallefont, V., Raftery, A.E., and Richardson, S., "Variable Selection and Bayesian Model Averaging in Case Control Studies", Statistics in Medicine, Volume 20, No. 21, pp. 3215-3230, 2001.

[14] Wintle, B.A., McCarthy, M.A., Volinsky, C.T., and Kavanagh, R.P., "The Use of Bayesian Model Averaging to Better Represent Uncertainty in Ecological Models", Conservation Biology, Volume 17, No. 6, pp. 1579-1590, 2003. 
[15] Snover, A., "Impacts of Global Climate Change on the Pacific Northwest", Seattle US Global Change Research Program and Office of Science and Tehcnology Policy, Pacific Northwest Regional Climate Change Workshop, 1997.

[16] Kmusser, "Columbia River Basin [Online image]", Retrieved August 16, 2016 from https://en.wikipedia.org.

[17] Volkman, J.M., "A River in Common: The Columbia River, the Salmon Ecosystem, and Water Policy", Western Water Policy Review Advisory Commission, 1997.

[18] Payne, J.T., Wood, A.W., Hamlet, A.F., Palmer, R.N., and Lettenmaier, D.P., "Mitigating the Effects of Climate Change on the Water Resources of the Columbia River Basin”, Climatic Change, Volume 62, No. 1-3, pp. 233-256, 2004.

[19] Maurer, E.P., Wood, A.W., Adam, J.C., Lettenmaier, D.P., and Nijssen, B., "A Long-Term Hydrologically Based Dataset of Land Surface Fluxes and States for the Conterminous United States", Journal of Climate, Volume 15, No. 22, pp. 3237-3251, 2002.

[20] Fowler, H.J., Blenkinsop, S., and Tebaldi, C., "Linking Climate Change Modelling to Impacts Studies: Recent Advances in Downscaling Techniques for Hydrological Modelling", International Journal of Climatology, Volume 27, No. 12, pp. 1547-1578, 2007.

[21] Moradkhani, H., Baird, R.G., and Wherry, S.A., "Assessment of Climate Change Impact on Floodplain and Hydrologic Ecotones", Journal of Hydrology, Volume 395, No. 3, pp. 264-278, 2010.

[22] Seguí, P.Q., Ribes, A., Martin, E., Habets, F., and Boe, J., "Comparison of Three Downscaling Methods in Simulating the Impact of Climate Change on the Hydrology of Mediterranean Basins", Journal of Hydrology, Volume 383, No. 1, pp. 111-124, 2010.

[23] Wood, A.W., Leung, L.R., Sridhar, V., and Lettenmaier, D.P., "Hydrologic Implications of Dynamical and Statistical Approaches to Downscaling Climate Model Outputs", Climatic Change, Volume 62, No. 1, pp. 189-216, 2004.

[24] Fisher, R.A., and Tippet, L., "Limiting Forms of the Frequency Distribution of the Largest or Smallest Member of a Sample", Mathematical Proceedings of the Cambridge Philosophical Society, Volume 24, No. 2, pp. 180-190, 1928.
El Adlouni, S., Ouarda, T.B.M.J, Zhang, X., Roy, R., and Bobee, B., "Generalized Maximum Likelihood Estimators for the Nonstationary Generalized Extreme Value Model", Water Resources Research, Volume 43, No. 3, 2007.

[26] Halmstad, A., Najafi, M.R., and Moradkhani, H., "Analysis of Precipitation Extremes with the Assessment of Regional Climate Models over the Willamette River Basin, USA", Hydrological Processes, Volume 27, No. 18, pp. 2579-2590, 2013.

[27] Katz, R.W., Parlange, M.B., and Naveau, P., "Statistics of Extremes in Hydrology", Advances in Water Resources, Volume 25, No. 8, pp. 1287-1304, 2002.

[28] Ekström, M., Fowler, H.J., Kilsby, C.G., and Jones, P.D., "New Estimates of Future Changes in Extreme Rainfall Across the UK Using Regional Climate Model Integrations. 2. Future Estimates and Use in Impact Studies", Journal of Hydrology, Volume 300, No. 1, 2005.

[29] Kharin, V.V., and Zwiers, F.W., "Changes in the Extremes in an Ensemble of Transient Climate Simulations with a Coupled Atmosphere-Ocean GCM", Journal of Climate, Volume 13, No. 21, pp. 3760-3788, 2000.

[30] Kharin, V.V., and Zwiers, F.W., "Estimating Extremes in Transient Climate Change Simulations", Journal of Climate, Volume 18, No. 8, pp. 1156-1173, 2005.

[31] Kharin, V.V., Zwiers, F.W., Zhang, X., and Hegerl, G.C., "Changes in Temperature and Precipitation Extremes in the IPCC Ensemble of Global Coupled Model Simulations", Journal of Climate, Volume 20, No. 8, pp. 1419-1444, 2007.

[32] Ajami, N.K., Duan, Q., and Sorooshian, S., "An Integrated Hydrologic Bayesian Multimodel Combination Framework: Confronting Input, Parameter, and Model Structural Uncertainty in Hydrologic Prediction”, Water Resources Research, Volume 43, No. 1, 2007.

[33] Hsu, K.-1., Moradkhani, H., and Sorooshian, S., “A Sequential Bayesian Approach for Hydrologic Model Selection and Prediction", Water Resources Research Volume 45, No. 122009.

[34] Raftery, A.E., Gneiting, T., Balabdaoui, F., and Polakowski, M., "Using Bayesian Model Averaging to Calibrate Forecast Ensembles", Monthly Weather Review, Volume 133, No. 5, pp. 1155-1174, 2005. 